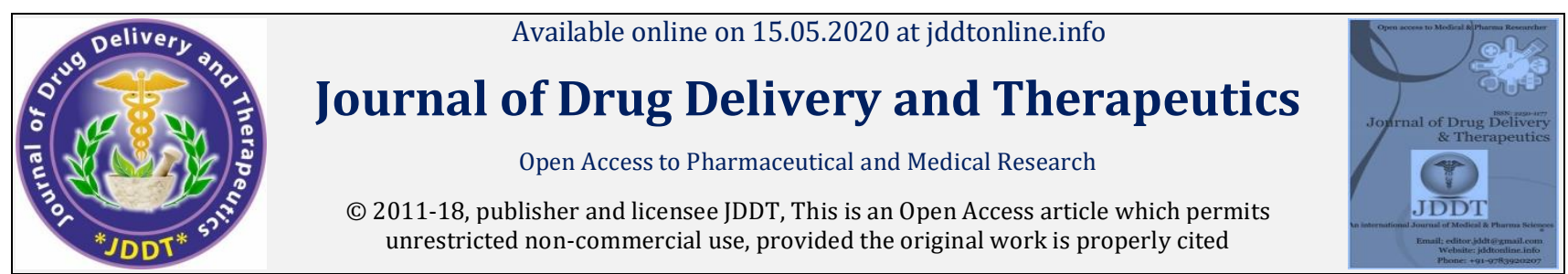

Open $\odot$ Access

Research Article

\title{
Ameliorative effect of hydroalcoholic extracts of Nigella sativa seed against CCl4-induced acute liver injury in rats
}

\author{
Uchendu Ikenna Kingsley \\ Department of Medical Laboratory Science, Faculty of Health Science and Technology, University of Nigeria, Enugu Campus, Enugu, Nigeria
}

\begin{abstract}
Objective: The aim of this study is to investigate the ameliorative effect of hydroalcoholic extract of Nigella sativa (HANS) against CCl 4 -induced hepatotoxicity in albino rats. Methods: Twenty five (25) albino rats, with average weight (105 $\pm 5 \mathrm{~g})$, were randomly grouped into five groups: AE, of five (5) rats per group. Group A rats served as normal control, Group B (Negative Control) received intraperitoneal administration of carbon tetrachloride $\mathrm{CCl}_{4}\left(0.4 \mathrm{ml} / \mathrm{kg}\right.$, i.p.) only, Group C received $\mathrm{CCl}_{4}$ and low dose $\mathrm{HANS}\left(400 \mathrm{mg} / \mathrm{kg}\right.$, oral), Group D received $\mathrm{CCl}_{4}$ and high dose HANS ( $800 \mathrm{mg} / \mathrm{kg}$, oral), and Group E (Positive control), received $\mathrm{CCl}_{4}$ and Vitamin C (200mg/kg, oral), for 3 days. Hepatotoxicity was assessed by measuring serum levels of total bilirubin, alanine aminotransferase (ALT), aspartate aminotransferase (AST), and alkaline phosphatase (ALP) using standard methods. Histopathological analysis of the liver was also carried out. Results: The extracts significantly stablized biochemical markers of hepatic injury, and preserved the histoarchitecture of the liver tissues against $\mathrm{CCl}_{4}$ damage. The protective effect was not dose-dependent, as low dose HANS $(400 \mathrm{mg} / \mathrm{kg})$, showed better protection than the high dose HANS $(800 \mathrm{mg} / \mathrm{kg})$. Conclusion: Hydroalcoholic extracts of Nigella sativa has antihepatotoxic effects.
\end{abstract}

Keywords: carbon tetrachloride, hepatotoxicity, medicinal plants, Nigella sativa, hydroalcoholic extract

Article Info: Received 17 March 2020; Review Completed 24 April 2020; Accepted 01 May 2020; Available online 15 May 2020

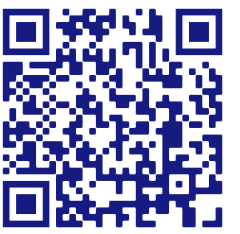

Cite this article as:

Uchendu IK, Ameliorative effect of hydroalcoholic extracts of Nigella sativa seed against CCl4-induced acute liver injury in rats, Journal of Drug Delivery and Therapeutics. 2020; 10(3):164-169 http://dx.doi.org/10.22270/jddt.v10i3.4006

*Address for Correspondence:

Uchendu Ikenna Kingsley, Department of Medical Laboratory Science, University of Nigeria, Enugu State, Nigeria

\section{INTRODUCTION}

Nigella sativa is a grassy plant, which has green to blue flowers with small black seeds ${ }^{1}$. It belongs to the botanical family of Ranunculaceae, which are approximately 2.5$3.5 \mathrm{~mm}$ and $1.5-2.0 \mathrm{~mm}$ in length and width respectively, with maximum height of about $40-70 \mathrm{~cm}^{2,3}$. The beneficial effects accredited to Nigella sativa, also known as black seed, are due to its composition of stable and volatile oils which contain good amounts of unsaturated fatty acids, arachidonic acid and eicosenoic acids in little amount ${ }^{3}$. It also consists of reasonable amounts of carotenoids, retinol, vitamin E, and thymoquinone (main active constituent); minerals like potassium, phosphorus amongst others, $, 1,3$. Traditional and medicinal uses of this seed ranges from soothing wounds to remedying cough, eczema, diabetes, inflammation of the bronchi and tooth aches ${ }^{3}$.

The liver is a vital organ that supports almost all other organs to a reasonable capacity. With respect to hepatoxicity, major symptoms of acute liver toxicity includes: weakness and fatigue, rapid onset of jaundice, abdominal pain, nausea and vomiting 4 . Although biotransformation process in the liver protects other organs and tissues in the body from harmful chemicals or toxins; the products of metabolic detoxification, if in excess, can cause damage to the liver; and an example of such toxic chemical product is Carbon tetrachloride $\left(\mathrm{CCl}_{4}\right)$.

ISSN: 2250-1177
Carbon tetrachloride $\left(\mathrm{CCl}_{4}\right)$ is an industrial and synthetic chemical that is capable of causing hepatotoxicity in experimental animals 5 . This is done through intraperitoneal intoxication, ingestion, or absorption through the skin. Trichloromethyl radical is produced from cytochrome $\mathrm{P} 450$ metabolism of carbon tetrachloride, and in combination with oxygen, forms peroxy-trichloromethyl which is a more reactive radical. Radicals like these, also produce alkoxy and peroxy radicals which cause tissue injury by binding to intracellular proteins, inactivation of enzymes, and form lipid peroxides in the cell membrane ${ }^{4,6}$.

Liver diseases have remained a huge burden to both clinicians and the patients; as the search for a new treatment that could safely and effectively prevent or reverse liver injuries remains a challenge. Several studies have been published that proved beneficial effects of plants and/or plant products 7-19; hence the need to unravel more medicinal plants with therapeutic potentials against debilitating diseases.

\section{MATERIALS AND METHODS}

\section{Plant material}

Fresh samples of Nigella sativa seeds were obtained from local market in Enugu, Nigeria. The plant material was authenticated by a consultant taxonomist at the the Department of Plant Science and Biotechnology, University CODEN (USA): JDDTAO 
of Nigeria. A voucher specimen was deposited at the herbarium with reference number UNH No 662 for future reference.

\section{Preparation of hydroalcoholic extracts of Nigella sativa (HANS)}

Nigella sativa seeds were dried and shaded from sun light, then powdered with a grinder. The extracts were prepared using Babaei et al. ${ }^{20}$ method with minor modifications. Six hundred (600) gram of Nigella sativa powder was macerated with 2 litres of 70\% methanol (as hydroalcoholic extract) for 72 hours. The mixture was stirred in an Erlenmeyer flask for 24 hours using a shaker. At the end of the extraction, the extract was filtered through a Whatman filter (Whatman Clifton, NJ, USA). The solvent was then allowed to evaporate using a water bath set at $30^{\circ} \mathrm{C}$, and $4 \mathrm{~g}$ of dried hydroalcoholic extracts was obtained. This was then reconstituted in distilled water, used to prepare the required concentration, and stored at $4^{\circ} \mathrm{C}$ until when needed for use.

\section{Acute toxicity test $\left(\mathrm{LD}_{50}\right)$}

This was performed on mice and Lorke ${ }^{21}$ procedure of LD50 determination was used.

\section{Phytochemical analysis of Nigella sativa}

Preliminary phytochemical screening of Nigella sativa was carried out using Trease and Evans method 22 .

\section{Chemical reagents and drugs}

The chemicals were of analytical grade, and are absolute methanol for plant extraction and $\mathrm{CCl}_{4}$ solution for induction of hepatotoxicity; and were purchased from Ogbete main market, Enugu. Drug used includes vitamin C (Alpha Pharmaceuticals, Enugu, Nigeria), used as reference drug (positive control). AST, ALT, ALP and total bilirubin kits were purchased from Randox Laboratories Ltd, UK.

\section{Preparation of vitamin C solution}

Stock concentrations $(20 \mathrm{mg} / \mathrm{ml})$ of vitamin C were prepared and used for the research.

\section{Induction of acute hepatotoxicity}

Liver injury was induced in each animal by intraperitoneal injection with $\mathrm{CCl}_{4}(0.4 \mathrm{ml} / \mathrm{kg})$ daily for 3 days.

\section{Animals and maintenance}

A total of twenty five (25) adult albino rats, weighing $(105 \pm 5 \mathrm{~g})$ were obtained from the animal house of the College of Veterinary Medicine, University of Nigeria. The animals were housed under standard condition. The experimental protocol was approved by the institution animal ethics committee of the University of Nigeria Teaching Hospital (UNTH/CSA. 876/VOL. 19).

\section{Experimental Design}

The twenty five (25) adult rats were grouped into (A-E) and given the following treatments daily and within 2 hours.

Group A: (Normal Control): No treatment was administered to this group.

Group B: (Negative Control): Received $\mathrm{CCl}_{4}(0.4 \mathrm{ml} / \mathrm{kg}$, i.p) only for 3 days.

Group C: Received $\mathrm{CCl}_{4}$ and low dose HANS (400mg/kg, oral) for 3 days.

Group D: Received $\mathrm{CCl}_{4}$ and high dose HANS $(800 \mathrm{mg} / \mathrm{kg}$, oral) for 3 days.

Group E (Positive Control): received $\mathrm{CCl}_{4}$ and Vitamin C $(200 \mathrm{mg} / \mathrm{kg}$, oral) for 3 days.

\section{Sample collection}

Blood samples for the determination of biochemical markers were taken by cardiac puncture of the left ventricle of the heart under chloroform anesthesia and the liver harvested for histopathological analyses.

\section{Biochemical analysis}

Measurement of serum ALT and AST were by colorimetric method as described by Reitman and Frankel23. Measurement of ALP was by colorimetric method as described by Kind and King ${ }^{24}$. Measurement of total bilirubin was by Colorimetric method as described by Malloy and Evelyn 25 .

\section{Histopathological analysis}

The excised liver was processed using the paraffin wax embedding technique, sectioned at 5 microns and stained using the Haematoxylin and Eosin [H and E] staining procedure 26 . The histological sections were examined using an Olympus ${ }^{\mathrm{TM}}$ light microscope.

\section{Statistical analysis}

Data analysis was done using GraphPad prism version 7.0 (GraphPad, San Diego, CA, USA). The results of the biochemical assays were reported as mean \pm SEM (standard error of mean). One way analysis of variance (ANOVA), followed by the Tukey post hoc analysis, was used to test for the level of significance $(\mathrm{p}<0.05)$.

\section{RESULTS}

Acute toxicity studies result. LD50 value of the extract was $2.4 \mathrm{~g} / \mathrm{kg}$ which indicates that the extract was safe.

\section{Phytochemical result}

The result of the preliminary phytochemical analysis of Nigella sativa revealed abundant presence of alkaloids and flavonoids $(+++)$; moderate presence of tannins and phenols $(++)$. However glycosides, saponins and steroids were absent (table 1)

Table 1: Qualitative phytochemical results of hydroalcoholic extract of Nigella sativa

\begin{tabular}{|c|c|}
\hline Test & Result \\
\hline Alkaloid & +++ \\
\hline Flavonoid & +++ \\
\hline Tannins & ++ \\
\hline Glycoside & - \\
\hline Phenol & ++ \\
\hline Saponin & - \\
\hline Terpenoid & - \\
\hline Steroid & - \\
\hline \multicolumn{2}{|c|}{ Key: $+++=$ present (in abundance); $++=$ present (in moderate }
\end{tabular}

$$
\text { amount); - = absent }
$$

\section{Biochemical results}

The functionality of the liver was established by estimating the serum level of the liver biochemical markers; ALT, AST, ALP and total bilirubin (table 2). A statistically significant $(\mathrm{P}<0.05)$ elevated levels of ALT, AST, ALP and total bilirubin were seen in $\mathrm{CCl}_{4}$-treated group $\mathrm{B}$ (negative control) when compared with group A (normal control) and group E (positive control) separately. However, co-administration of $\mathrm{CCl}_{4}$ with high and low doses of hydroalcoholic extracts of Nigella sativa (HANS) separately, restored the level of these parameters to near normal when compared with $\mathrm{CCl}_{4-}$ treated group (negative control). Again, we observed the extracts did not show a dose-dependent protection, as the 
Table 2: Statistical comparison of kidney biochemical concentrations in different experimental animal groups

\begin{tabular}{|c|c|c|c|c|}
\hline Groups & ALT (IU/L) & AST (IU/L) & ALP (IU/L) & Total bilirubin (mmol/l) \\
\hline A: Normal Control & $20.65 \pm 2.73^{* *}$ & $0.60 \pm 0.06^{* *}$ & $4.73 \pm 0.43^{*}$ & $133.42 \pm 1.76^{*}$ \\
\hline B: $\mathrm{CCl}_{4}$ Alone & $40.33 \pm 4.91$ & $1.43 \pm 0.09$ & $6.93 \pm 0.52$ & $123.71 \pm 2.03$ \\
\hline C: $\mathrm{CCl}_{4}+\mathrm{HANS}(400 \mathrm{mg} / \mathrm{kg})$ & $22.69 \pm 1.45^{*}$ & $0.69 \pm 0.18^{*}$ & $5.10 \pm 0.55$ & $130.68 \pm 1.45^{*}$ \\
\hline D: $\mathrm{CCl}_{4}+\mathrm{HANS}(800 \mathrm{mg} / \mathrm{kg})$ & $23.87 \pm 2.33^{*}$ & $0.70 \pm 0.06^{*}$ & $5.14 \pm 0.54$ & $131.02 \pm 1.81^{*}$ \\
\hline E: $\mathrm{CCl}_{4}+$ Vit. C $(200 \mathrm{mg} / \mathrm{kg})$ & $20.68 \pm 1.72^{* *}$ & $0.65 \pm 0.13^{* *}$ & $4.70 \pm 0.25^{*}$ & $131.00 \pm 2.65^{*}$ \\
\hline
\end{tabular}

Values given as Mean \pm SEM. ${ }^{* *} \mathrm{p}<0.01$ or ${ }^{*} \mathrm{p}<0.05$ is significant when $\mathrm{CCl}_{4}$ alone (negative control) is compared with all other groups.

\section{Histopathological results}

The liver of normal control rats appeared functionally and structurally normal. The hepatocytes showed a well conserved morphology (1A). The Liver of $\mathrm{CCl}_{4}$-treated group (negative control) showed abnormal changes; there was vacuolation of the hepatocytes with infiltration by inflammatory cells (1B). However, the hepatocytes of test group rats (low dose HANS at $400 \mathrm{mg} / \mathrm{kg}$ ) were normal; but there was mild infiltration of inflammatory cells around the central vein $(1 \mathrm{C})$. While in the other test group rats (high dose HANS at $800 \mathrm{mg} / \mathrm{kg}$ ), the hepatocytes appear normal with widened sinosoids (1D). The liver section of group $\mathrm{E}$ (positive control) appeared normal, and hepatocytes and central vein all appeared normal (1E).
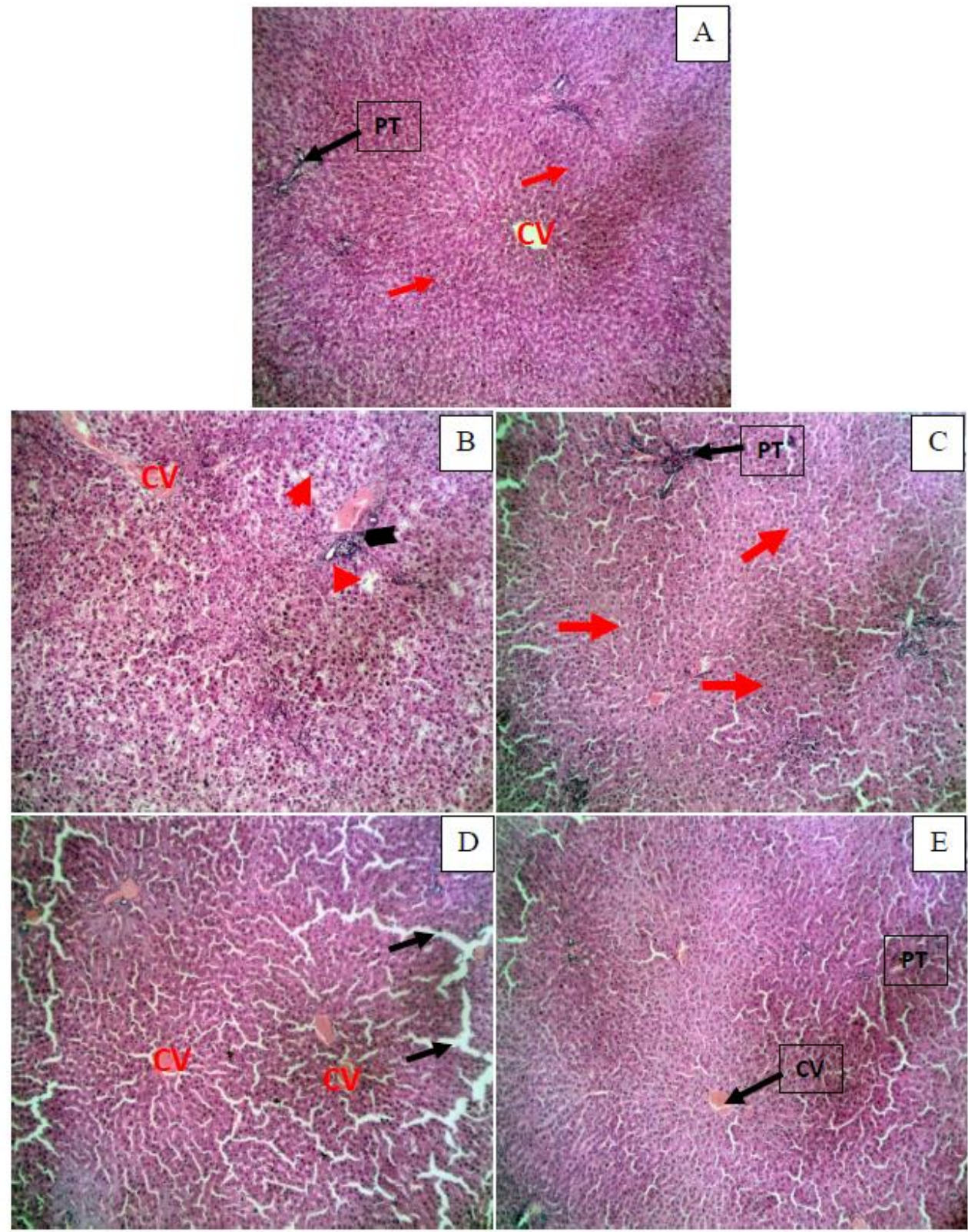

Figure 1: Photomicrograph of liver section. (A) Liver section appears normal. Hepatocytes (arrow); central vein (CV) and portal triad (PT) all appear normal. (B) Hepatocytes appear moderately normal and significantly vacuolated (red arrow heads). There is presence of periportal inflammation (black arrow head), CV - central vein. (C) Hepatocytes (arrows) are normal with no signs of degenerative lesions/changes. CV central vein, PT - portal triad. (D) Hepatocytes are normal; the sinusoids are widened (black arrow). CV - central vein. (E) Section shows normal histoarchitecture. CV - central vein, PT - portal triad [Stain: H and E; ×100] 


\section{DISCUSSION}

The liver is one of the most essential and efficient organs in the body. It carries out numerous functions. The liver is the main metabolic organ in the body, including metabolism of harmful chemical substances 27-30.

Ingestion or exposure to chemicals poses a serious health risk. Early intervention against cellular or biochemical changes induced by such events is vital to help prevent organ damage 31

Carbon tetrachloride $\left(\mathrm{CCl}_{4}\right)$, recognized as an experimental toxin, mainly causes acute liver damage through production of free radicals. $\mathrm{CCl}_{4}$ as well induces renal dysfunction; hence renal failure is often related with the end-stage of the hepatic damage 4 .

Despite all studies performed to date, therapy choices for liver injury are very few. Plants have proven to be most useful in the treatment of diseases in most of the developing countries, and they provide important sources of most of the world's pharmaceutical; thus they have served a valuable starting material for drug development ${ }^{32}$.

Recently, the role of diet in human health has received considerable attention. The observations in this study could partly be attributed to the phytochemical compounds which possess antioxidation 4,33 .

Preliminary phytochemical analysis of Nigella sativa showed the presence of alkaloids, flavonoids, tannins and phenols with abundant presence of alkaloids and flavonoids compared to the moderate presence of tannins and phenols. These phytochemicals have been reported for their effective antioxidative properties 34,35 . The hepatoprotective effect of Nigella sativa was displayed by the reduction of elevated serum liver enzyme markers; ALT, AST, ALP, and bilirubin as observed from the biochemical results of Groups C and D. The photomicrography (histopathology) of rats from these groups also showed normal hepatocytes, when compared with the photomicrography of rats from Group B $\left(\mathrm{CCl}_{4}\right.$ group), suggesting that the attenuation could be due to the effects of the antioxidative property of the phytochemicals present in the extract. The hydroalcoholic extracts of Nigella sativa probably worked to maintain the structural integrity of the plasma membrane of the liver cells to protect it against breakage by the reactive metabolites formed from exposure to $\mathrm{CCl}_{4}$, and reducing lipid peroxidation which protected against further destruction of the hepatocytes, and this agrees with reports from other studies 36,37 . Therefore, it could be safe to say that the secondary metabolites (flavonoids, phenols, tannins and alkaloids), present in the seed extracts, played an important role in restoring tissue architecture and liver function as observed in the histological and biochemical results. The importance of dosage cannot be underemphasized, as low dose hydroalcoholic extracts of Nigella sativa (HANS) provided a much better ameliorative effect than the high dose.

Although this present study was not aimed to evaluating the mechanism through which the seed extract showed ameliorative effects; it was however observed that the extract, particularly the low dose, acted in similar way as the standard drug (Vitamin C), a known antioxidant, which was used as reference drug (Table 2 and Figure 1). Interestingly, there was no dose-dependent protection by the seed extract; since the extract was more protective at low dose than at high dose. The findings (ameliorative effects) observed in this study could be as a result of the singular or combined actions of one or more of these bioactive phytochemical constituents present in the hydroalcoholic extracts of Nigella sativa.

In this study, administration of high dose hydroalcoholic extracts of Nigella sativa (HANS) $(800 \mathrm{mg} / \mathrm{kg})$ in the rats did not show much better protection than the low dose as expected, rather the extract showed signs that it could be toxic at high dose. According to report by Dirican et al. ${ }^{38}$, Thymoquinone (TQ) (the most abundant and active compound in Nigella sativa) has dual role depending on the cellular microenvironment; it may act as an antioxidant or a prooxidant. In a normal cell, TQ acts as an antioxidant, whereas in tumors or diseased tissue, TQ induces ROS production 39,40 . One serious drawback with $\mathrm{TQ}$ is its toxicity at high doses and poor water solubility which thus limits its usage as a therapeutic agent ${ }^{40}$. This could be the reason for the diminished protection upon administration of high dose of the extract. In addition, the solvent used for extraction could also play a crucial role in the concentration of thymoquinone. According to report by Saleh et al.41, methanol is much more effective in extracting the main bioactive component (TQ) of Nigella sativa at high concentration; and the solvent used for extraction conprised $70 \%$ methanol against 30\% water. Since it has been earlier reported that the ability of Nigella sativa in scavenging free radicals could be as a result of synergism between its phytochemical components; the much lower protection at high dose could then be as a result of TQ, bearing in mind that its concentration is much more than other phytochemical constituents and this agrees with the reports of AbuKhader, cited in Ahamdi et al.42, who reported that at $500 \mathrm{mg} / \mathrm{kg}$, oral administration of methanol extracts of Nigella sativa became toxic to the rats used for study.

Thymoquinone, is a constituent of flavonoids ${ }^{43}$. Flavonoids are natural antioxidants that occur in fruits, vegetables flowers and seeds which are very important in human diet ${ }^{44}$. Flavonoids have high antioxidant and anti- free radical effects 45,46 . They have the ability to reduce free radical formation and to scavenge free radicals from blood, thereby preventing cell injury ${ }^{47}$.

\section{CONCLUSION}

This present study shows that carbon tetrachloride induced liver injury; however, administration of hydroalcoholic extract of Nigella sativa ameliorated the effects, thereby offering significant protection. Thus data provides a scientific proof that extract of Nigella sativa could be of health benefits

\section{ACKNOWLEDGEMENT}

The author expresses deep sense of gratitude to management of Eastern Nigeria Medical Centre, Enugu and all the technical staff for their kind cooperation.

\section{CONFLICT OF INTEREST}

Not applicable

\section{SOURCE OF FUNDING}

This study was self- funded.

\section{REFERENCES}

1. Hosseini M, Mohammadpour T, Karami R, Rajaei Z, Sadeghnia HR, Soukhtanloo M. Effects of the hydro-alcoholic extract of Nigella sativa on scopolamine-induced spatial memory impairment in rats and its possible mechanism. Chinese Journal of Integrative Medicine. 2015; 21(6):438-444 
2. Tavakkoli A, Ahmadi A, Razavi BM, Hosseinzadeh H. A review of miracle herb: Nigella sativa. Iran J Pharm Res. 2017; 16:223.

3. Amin B, Hosseinzadeh H. Black cumin (Nigella sativa) and its active constituent, thymoquinone: an overview on the analgesic and anti-inflammatory effects. Planta Medical. 2015; 82:8-16

4. Uchendu IK, Nnedu EB, Orji OC. Combination of aqueous extracts of curcuma longa (turmeric) and some calcium channel blockers synergistically improves $\mathrm{CCl}_{4}$-induced hepatotoxicity in albino rats. Pharmacologyonline. 2018; 3:392-401

5. Rahmat AK, Muhammad RK, Sumaira S, Mushtaq A, Naseer AS. Carbon tetrachloride induced lipid peroxidation and hyperglycemia in rat: A novel study. Toxicology and Industrial Health. 2015; 31(6):546-553.

6. Hismiogullari AA, Hismiogullari SE, Karaca O, Sunay FB, Paksoy S, Can M, Seyrek K, Yavvz O. The protective effect of curcumin administration on $\mathrm{CCl}_{4}$ - induced nephrotoxicity in rats. Pharmacology Report. 2015; 67:410-416.

7. Uchendu IK, Nnedu EB, Ekeigwe IB, Nigella sativa seed extract protects against cadmium-induced cardiotoxicity in rats, Journal of Drug Delivery and Therapeutics. 2020; 10(1-s):174177.

8. Uchendu IK, Ekeigwe IB, Nnedu EB, Antidyslipidaemic and cardioprotective effects of turmeric (Curcuma longa) in rat fed a high cholesterol diet, Journal of Drug Delivery and Therapeutics. 2020; 10(1-s):178-181.

9. Uchendu IK, Agu CE. Anti-nephrotoxic and antihyperlipidaemic potentials of aqueous extracts of turmeric (curcuma longa) in hypercholesterolaemic albino rat. Pharmacologyonline. 2018; 3:1-11

10. Uchendu IK, Nnedu EB, Orji OC. Combination of aqueous extracts of Cucuma longa and some calcium channel blockers synergistically improves CCl4-induced hepatotoxicity in albino rats. Pharmacologyonline 2018; 3: 392-401.

11. Kingsley UI. Effects of tomato extract (lycopersicon esculentum) on carbimazole-induced alterations in kidney of albino rats. International Journal of Research and. Review. 2018; 5:72-79.

12. Nnedu EB, Uchendu IK, Orji OC. The role of crude methanol leaf extract of moringa oleifera in protection against hyperlipidaemia and cardiomyopathy in albino rat fed a high cholesterol diet and carbimazole. pharmacologyonline 2018; 3:261-271.

13. Uchendu IK, Agu CE, Orji OC, Nnedu EB, Arinze C, Uchenna AC, Okongwu UC. Effect of tomato (lycopersicon esculentum) extract on acetaminophen - induced acute hepatotoxicity in albino wistar rat. Bioequivalence and Bioavailability International Journal; 2018, 2(1):000119.

14. Orji OC, Uchendu IK, Agu CE, Nnedu EB, Okerreke AN, Orji GC. Combined effects of vitamin $\mathrm{c}$ and tomato extract (lycopersicon esculentum) on carbimazole-induced alterations in the testes of male albino rats. Indian Journal of Physiology and Pharmacology. 2018; 62(3):380-384.

15. Ikenna, K.U.; Chidozie, E.A.; Oliver, C.O.; Eluke, B.C.; Ikechukwu, J.C., Nnedu, E.B., Tochi, F.N. and Oluwanifemi, P.A. Effect of Soy (Glycine max) Against Alcohol-Induced Biochemical Alteration in Liver of Male Albino Rat. Der Pharma Chemica; 2017, 9 (16):115-119.

16. Uchendu IK, Orji OC, Agu CE. Attenuation of glycerol-induced acute renal failure in albino rats by soy beans (Glycine max). International Journal of ChemTech Research 2017; 10(12):165-172.

17. Anioke I, Okwuosa C, Uchendu I, Chijioke O, Dozie-Nwakile O, Ikegwuonu I, Kalu P, Okafor M. Investigation into hypoglycemic, antihyperlipidemic, and renoprotective potentials of Dennettia tripetala (Pepper Fruit) Seed in a Rat
Model of Diabetes. Hindawi BioMed Research International, 2017; Article ID6923629, 11pages

18. Ikenna, K.U., Okechukwu, K.O., Chidozie, E.A, Oliver, C.O., Blessing, E.C. and Tochi, F.N. Hypolipidaemic and renoprotective effects of glycine max (soy bean) against lipid profile and renal biochemical alterations in hypercholesterolemic rat. International Journal of Biomedical Research. 2016, 7(12):822-828.

19. Kingsley U.I., Steven O.O., Agu C.E.; Orji O.C., Chekwube B.E., Nwosu T. F. Anti-hyperlipidemic effect of crude methanolic extracts of Glycine max (soy bean) on high cholesterol diet-fed albino rats. Journal of Medical and Allied Science., 2017, 7 (1):34-40

20. Babaei HA, Motamedifar M, Khalifat S, Mohammadi A, Khosrow Z, Motamedifar A. In vitro study of antibacterial property and cytotoxic effects of aqueous, ethanolic, methanolic, and hydroalcoholic extracts of fenugreek seed. Pakistan Journal of Medical and Health Sciences. 2018; 12(2): 906-910.

21. Lorke D. A new approach to practical acute toxicity testing. Archive of Toxicology. 1983; 54(4):275-287.

22. Trease G, Evans SM. Pharmacognosy: (15th Edition). English Language Book Society. Bailliere Tindall, London, 2002. pp. 23-67.

23. Reitman S. and Frankel SA. "Colorimetric method for determination of serum glutamate oxaloacetate and glutamic pyruvate transaminase". Am. J. Clin Pathol. 1957; 28:56-58.

24. Kind PR and King EJ. Colorimetric method for determination of serum alkaline phosphatase. J. Clin Pathol. 1954; 7:322.

25. Malloy HT and Evelyn KA. "The determination of bilirubin with the photoelectric colorimetric method". Journal of Biological Chemistry 1937; 119:481-490.

26. Baker FJ, Silverton RE, Pallister CJ Baker and Silverton's Introduction to Laboratory Technology. 7th Edition, Butterworth-Heinemann, Wobrun, MA, USA, 1998; page 448.

27. Ding HR, Wang JL, Ren HZ, Shi XL. Lipometabolism and glycometabolism in liver diseases. BioMedical Research International. 2018; 2018: ID 1287127, 7 pages.

28. Champe PC, Harvey RA, Ferrier DR. Lippincotts Illustrated Reviews: Biochemistry, $4^{\text {th }}$ Edition. Wolters Kluwer Health, Lippincott Williams and Wilkins, New York. 2008; pp251-284.

29. Cox MM, Nelson DL. Lehninger Principle of Biochemistry $4^{\text {th }}$ Edition. W. H. Freeman and Company, New York. 2005; pp238-276.

30. Allen JH. The wicked problem of chemicals policy: opportunities for innovation. Journal of Eenvironmental Science 2013; 3:101-8

31. Schyman P, Printz RL, Estes SK, , Boyd KL, Shiota M, Wallqvist A. Identification of the toxicity pathways associated with thioacetamide-induced injuries in rat liver and kidney. Frontiers of Pharmacology. 2018; 9:1272.

32. Ajibesin KK. Dacryodes edulis (G. Don) HJ. Lam: A review on its medicinal, phytochemical and economic properties. Research Journal of Medicinal Plant 2011; 5(1):32-41.

33. Ekeigwe IB, Ikegwuonu IC, Uchendu IK, Uchenna CA , Okongwu UC. Curcuma longa aqueous extract prevents myocardial injury in hypercholesterolaemic albino rat. Ukrainian Biochemical Journal. 2019; 91(4):50-57.

34. Bourgou S, Pichette A, Marzouk B, Legault J. Bioactivities of black cumin essential oil and its main terpenes from Tunisia. South African Journal of Botany. 2010; 76:210-216.

35. Pieta PG. Flavonoids as antioxidants. Journal of Natural Products. 2000; 63(7):1035-1042.

36. Essawy AE, Abdel-Moneim AM, Khayyat L, Elzergy AA. Nigella sativa seeds protect against hepatotoxicity and dyslipidaemia 
induced by carbon tetrachloride in mice. Journal of Applied Pharmaceutical Science. 2012; 2 (10):21-25.

37. Al-Razzuqi R, Hussaini J, Al-Jeboori A. A protective effect of nigella sativa against carbon tetrachloride-induced liver injury in experimental rabbit models. International Journal of Green Pharmacy 2011; 5(3):198-200.

38. Ismail $\mathrm{N}$, Ismail $\mathrm{M}$, Azmi HN, Bakar AFM, Basri $\mathrm{H}$, Abdullah AM. Modulation of hydrogen peroxide-induced oxidative stress in human neuronal cells by thymoquinone-rich fraction and thymoquinone via transcriptomic regulation of antioxidant and apoptotic signaling genes. Oxidative Medicine and Cellular Longevity. 2016; 2016:2528935.

39. Paarakh MP. Nigella sativa Linn - A comprehensive review. Indian Journal of Natural Products and Resources. 2010; $1(4): 409-429$.

40. Khan AM, Afzal M. Chemical composition of Nigella sativa Linn: part 2 recent advances. Inflammopharmacology. 2016; 24:67-79.

41. Saleh FA, El-Darra N, Raafat K, Ghazzawi IE. . Phytochemical analysis of Nigella sativa L. Utilizing GC-MS exploring its antimicrobial effects against multidrug-resistant bacteria. Pharmacogsy Journal. 2018; 10(1):99-105.
42. Ahmadi M, Scurtu M, Tulcan C, Boldura O, Milovanov C, Hutu I, Mircu C, Radulov I, Dronca D. Nigella sativa - a plant with personality in biochemistry and experimental medicine researches. Bulletin UASVM veterinary medicine. 2016; 73(2):203-209.

43. Darakhshan S, Pour AB, Colagar AH, Sisakhtnezhad S. Thymoquinone and its therapeutic potentials. Pharmacological. Research. 2015; 95-96:138-158.

44. Cherrak SA, Mokhtari-Soulimane N, Berroukeche $F$ Bensenane B, Cherbonnel A, Merzouk $\mathrm{H}$, Elhabiri M. In vitro antioxidant versus metal ion chelating properties of flavonoids: A structure-activity investigation. Plos One. 2016; 11(10):e0165575.

45. Mahmoud AM, Bautista RJH, Sandhu MA, Hussein OE Beneficial effects of citrus flavonoids on cardiovascular and metabolic health. Oxidative Medicine and Cellular Longevity. 2019; 2019:19.

46. Kooti W, Hasanzadeh-Nooti Z, Sharafi-Ahvazi N, Asadi-Samani M, Ashtary-Larky D. Phytochemistry, Pharmacology and therapeutic uses of black seed (Nigella Savita). Chin J Nat Medicines. 2016; 14(10):732-745.

47. Panche AN, Diwan AD, Chandra SR. Flavonoids: an overview. Journalof Nutritional Science, 2016; 5:1-15. 